\title{
Targeting the Potassium Channel Kv1.3 Kills Glioblastoma Cells
}

\author{
Elisa Venturinia ${ }^{a}$ Luigi Leanza $^{b}$ Michele Azzolinic Stephanie Kadow ${ }^{a}$ \\ Andrea Mattarei $^{d}$ Michael Wellere Ghazaleh Tabatabaif ${ }^{f}$ Michael J. Edwards ${ }^{g}$ \\ Mario Zorattic Cristina Paradisid Ildikò Szabòo ${ }^{b, c}$ Erich Gulbins $^{a, g}$ \\ Katrin Anne Beckera
}

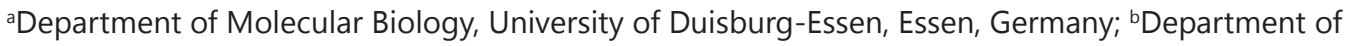
Biology, University of Padova, Padova, Italy; 'CCNR Institute of Neurosciences and Department of Biomedical Sciences and Neuroscience Center, University of Padova, Padova, Italy; dDepartment of Chemical Sciences, University of Padova, Padova, Italy; eLaboratory of Molecular Neuro-Oncology, Department of Neurology and Neuroscience Center, University Hospital and University of Zurich, Zurich, Switzerland; Interdisciplinary Division of Neuro-Oncology, Departments of Vascular Neurology and Neurosurgery, University Hospital Tübingen, Tübingen, Germany; ${ }^{9}$ Department of Surgery, University of Cincinnati, Cincinnati, USA

\section{Key Words}

Kv1.3 • Inhibitors $•$ Glioblastoma $・$ Mitochondria

\begin{abstract}
Background/Aims: Glioblastoma (GBM) is one of the most aggressive cancers, counting for a high number of the newly diagnosed patients with central nervous system (CNS) cancers in the United States and Europe. Major features of GBM include aggressive and invasive growth as well as a high resistance to treatment. Kv1.3, a potassium channel of the shaker family, is expressed in the inner mitochondrial membrane of many cancer cells. Inhibition of mitochondrial Kv1.3 was shown to induce apoptosis in several tumor cells at doses that were not lethal for normal cells. Methods: We investigated the expression of Kv1.3 in different glioma cell lines by immunocytochemistry, western blotting and electron microscopy and analyzed the effect of newly synthesized, mitochondria-targeted, Kv1.3 inhibitors on the induction of cell death in these cells. Finally, we performed in vivo studies on glioma bearing mice. Results: Here, we report that Kv1.3 is expressed in mitochondria of human and murine GL261, A172 and LN308 glioma cells. Treatment with the novel Kv1.3 inhibitors PAPTP or PCARBTP as well as with clofazimine induced massive cell death in glioma cells, while Psora-4 and PAP-1 were almost without effect. However, in vivo experiments revealed that the drugs had no effect on orthotopic brain tumors in vivo. Conclusion: These data serve as proof of principle that Kv1.3 inhibitors kills GBM cells, but drugs that act in vivo against glioblastoma must be developed to translate these findings in vivo.




\section{SiqínAis}

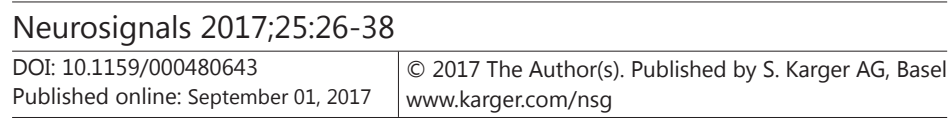

Venturini et al.: Kv1.3 Inhibition Kills Glioblastoma Cells

\section{Introduction}

Glioblastoma (GBM) is one of the most aggressive cancers and is the most common malignant brain tumor in adults, counting for nearly half of the 23,000 patients diagnosed with CNS cancers every year in the United States [1]. The current standard of care for GBM, established in 2005, includes, after maximal surgical rejection, temozolomide (TMZ)-based chemotherapy in combination with radiation therapy [2]. However, median patient survival does not exceed 15 months after diagnosis, due to recurrence and lack of treatments [3]. Recently, the US Food and Drug Administration (FDA) approved bevacizumab as a new drug for the treatment of glioblastoma, but whether the drug really improves patient survival remains to be determined [4]. A major problem in the treatment of GBM is the high resistance of these tumor cells to chemotherapy and irradiation and, therefore, novel treatment options must be developed.

The Kv1.3 channel, belonging to the potassium $\left(\mathrm{K}^{+}\right)$channels shaker family, has been demonstrated to be expressed in several cancer cell lines [5-7]. In addition to the plasma membrane, Kv1.3 was identified in the inner mitochondrial membrane (IMM), where it was shown to play a critical role in the induction of apoptosis [8]. It has been demonstrated that mitochondrial Kv1.3 (mitoKv1.3) interaction with the pro-apoptotic protein Bax or toxins, able to block the channel, is sufficient to induce cytochrome c release and outer membrane permeabilization in mitoKv1.3-positive isolated mitochondria, whereas mitoKv1.3-deficient mitochondria were resistant to the same stimuli [9]. Mechanistically, a functional interaction between Bax and the channel protein was found [9], which was determined by a positively charged conserved lysine at position 128 of Bax protruding into the intermembrane space facing the IMM after Bax insertion into the outer mitochondrial membrane [10]. Mutation of this amino acid abrogated the apoptotic effects of Bax in both isolated mitochondria and in intact cells expressing the mutated protein $[9,11]$. Since then, specific membrane permeant inhibitors, including the Ruta graveolens plant derived psoralens Psora-4, and PAP-1, the anti-mycobacterial drug clofazimine and novel mitochondrial targeted PAP-1 derivatives, namely PAPTP and PCARBTP, synthesized by our group, were used to mimic the interactions of Bax and mitoKv1.3 in different cancer cell lines that express Kv1.3 [12, 13]. These Kv1.3 inhibitors were shown to induce the intrinsic apoptotic pathway in multiple human and murine mitoKv1.3-expressing cells including Jurkat T lymphoma, osteosarcoma SAOS-2, B16F10 melanoma cells as well as human pancreas cancer cells and B-lymphocyte chronic leukemia cells, whereas cells displaying a low or no Kv1.3 current, such as K562, or human primary skin fibroblasts did not undergo apoptosis when treated with these inhibitors [13, 14]. Importantly, clofazimine and the recently developed mitochondria-targeted inhibitors of Kv1.3 PAPTP and PCARBTP showed more than 90\% tumor reduction in an in vivo B16F10 mouse melanoma model $[13,14]$ without causing obvious side-effects. Kv1.3 channel blockers were further used ex vivo in primary B cells from chronic lymphocytic leukemia (B-CLL) patients $[12,13]$. Characterized by a higher level of functional Kv1.3 channel compared to non-malignant B and T cells of the same patient or of healthy subjects, patients' B-CLL cells underwent cell death after inhibition of Kv1.3, whereas non-malignant lymphocytes, expressing less Kv1.3, were spared [12,13].

In the present work, we investigated Kv1.3 expression in a murine (GL261) and two human (A172, LN308) glioma cell lines, and applied a panel of Kv1.3 inhibitors to define their sensitivity to these compounds. We found that, in comparison to PAP-1 and Psora-4, which caused a maximum of $30 \%$ cell death, clofazimine and the newly designed, mitochondriatargeted drugs, i.e. PAPTP and PCARBTP, triggered massive death of glioma cells in vitro. Mechanistically, we demonstrated that inhibition of Kv1.3 results in a release of cytochrome c from mitochondria. However, in vivo experiments failed to show an effect of the drugs on orthotopic glioma. 


\section{Materials and Methods}

\section{Cells and drugs}

GL261, A172 and LN308 cells were previously described [15-17]. All three cell lines were grown in Dulbecco's modified eagle medium (DMEM, Gibco/Invitrogen, Darmstadt, Germany) supplemented with $10 \%$ fetal calf serum (FCS), $10 \mathrm{mM}$ HEPES, $2 \mathrm{mM}$ L-glutamine, $0.1 \mathrm{U} / \mathrm{ml}$ penicillin, $0.1 \mu \mathrm{g} / \mathrm{ml}$ streptomycin, non-essential amino acids, $1 \mathrm{mM}$ sodium-pyruvate at $37^{\circ} \mathrm{C}$ with $10 \% \mathrm{CO}_{2}$. PAP-1, Psora-4 and clofazimine were from Sigma Aldrich, PAPTP and PCARBTP were synthesized by us as previously described [13]. All drugs were dissolved in dimethyl sulfoxide (DMSO) and diluted in DMEM. The final concentration of DMSO was $\leq 0.5 \%$ in all assays.

\section{Trypan blue assay}

To assess cell viability, $0.05 \times 10^{6}$ cells were seeded in a 12 well plate and allowed to grow in DMEM for $24 \mathrm{hrs}$. After treatment, cells were trypsinized, collected, resuspended in PBS and added to 0.4\% Trypan blue solution (Sigma Aldrich). Viable and non-viable cells were counted by light microscopy.

\section{Western blot}

Samples were dissolved in $5 \mathrm{x}$ sample buffer $(250 \mathrm{mM}$ Tris, $\mathrm{pH} 6.8,20 \%$ glycine, 4\% SDS, 8\% $\beta$-mercaptoethanol, $0.2 \%$ bromophenol blue) and $40 \mu$ g loaded on a $10 \%$ or $12 \%$ SDS-PAGE, then transferred to either a nitrocellulose or polyvinyl difluoride (PVDF) membrane (Pall Corporation, Pensacola, FLA, USA). We used the following primary antibodies: anti-Kv1.3 (1:200, Alomone Labs APC-101 or 1:1,000 Pineda); anti-Tom20 (1:1,000, BD Pharmingen, San Diego, USA); anti-Tim23 (1:500, BD Pharmingen, San Diego, USA); anti-tubulin alpha (1:1,000, Epitomics, CA, USA); anti-cytochrome c 1 :2,000, BD Pharmingen, San Diego, USA); anti-GADPH (1:500, EMD Millipore, USA). Secondary anti-rabbit or anti-mouse antibodies were horseradish peroxidase- or alkaline phosphatase-conjugated (Santa Cruz Biotechnology, CA, USA) and used with chemiluminescence detection (Thermo Fisher Scientific Inc. or Perkin Elmer, Waltham, MA, USA) to develop the blots.

\section{Cytometry}

To asses Kv1.3 expression by flow cytometry, cells were collected and re-suspended with $1 \mu \mathrm{g}$ FITCanti-Kv1.3 (Sigma, Deisenhofen, Germany) in DMEM w/o phenol red and w/o FCS for $1 \mathrm{~h}$ at $4^{\circ} \mathrm{C}$. To detect cell death via apoptosis, cells were treated or left untreated in a 12 well plate for $24 \mathrm{hrs}$. After treatment, cells were trypsinized, collected, washed once with Annexin V binding buffer (10 mM HEPES pH 7.4, 140 $\mathrm{mM} \mathrm{NaCl}, 5 \mathrm{mM} \mathrm{CaCl}_{2}$ ), pellets were resuspended in the same buffer containing Annexin V-Fluos (1:100, Roche, Mannheim, Germany) and incubated for 15 min at RT in the dark. In both cases, samples were analyzed using a FACSCalibur flow cytometer (BD Biosciences) $(\lambda=488 \mathrm{~nm})$. Data were processed with a BD CellQuest Pro software.

\section{Cell membrane fraction enrichment}

To detect channels in membrane enriched fractions we used the protocol reported previously [7]. Briefly, cells were seeded in a $100 \mathrm{~mm}$ tissue culture dish for $24 \mathrm{hrs}$. Cells were then washed once in $0.9 \%$ $\mathrm{NaCl}$, collected in ice-cold lysis buffer (5 mM Tris/HCl pH 7.4, 0.25 \% Triton X-100, 1 mM EDTA, 1 mM DTT, $0.2 \mathrm{M} \mathrm{NaCl}$, protease inhibitors), vortexed, $15 \mu \mathrm{l}$ of $4 \mathrm{M} \mathrm{NaCl}$ were added, samples were vortexed again and broken cells were collected at 20,000 x g for $10 \mathrm{~min}$ at $4^{\circ} \mathrm{C}$. The pellet was re-suspended in ice-cold lysis buffer, loaded on a 10\% SDS-PAGE and blotted on a PDVF membrane with the indicated antibodies.

\section{Mitochondria isolation}

Mitochondria from glioma cells were purified by differential centrifugation as described previously [18]. Briefly, approximately $2 \times 10^{8}$ cells were washed twice in PBS and gently scraped off the culture plate. After washing twice in PBS, the pellet was re-suspended in TES buffer (30 mM sucrose, $10 \mathrm{mM}$ TES pH 7.4, $1 \mathrm{mM}$ EGTA pH 7.4) and dounce homogenized. The lysate was centrifuged at $600 \mathrm{x} \mathrm{g}$ for $10 \mathrm{~min}$ at $4^{\circ} \mathrm{C}$. The pellet was processed again as above to maximize the recovery. The two supernatants were combined and centrifuged at $800 \mathrm{xg}$ for $10 \mathrm{~min}$ at $4^{\circ} \mathrm{C}$ to remove unbroken cells. The supernatant was centrifuged at 
$8,000 \mathrm{xg}$ for $10 \mathrm{~min}$ at $4^{\circ} \mathrm{C}$ to pellet mitochondria, which were re-suspended in a small volume of TES buffer. Mitochondria were further purified in a discontinuous Percoll gradient $(60,30$ and $18 \%$ Percoll in TES buffer) by centrifugation at $8,500 \mathrm{xg}$ for $10 \mathrm{~min}$ at $4^{\circ} \mathrm{C}$. The fraction at the lower interface was collected and washed three times in TES buffer at $20,000 \mathrm{x}$ g for $10 \mathrm{~min}$ at $4^{\circ} \mathrm{C}$. The final pellet was re-suspended in TES buffer, loaded on a 10\% SDS-PAGE and blotted on a nitrocellulose membrane with the indicated antibodies.

Cytochrome c release assay

To detect the release of cytochrome c, GL261 cells were treated or left untreated for 16 hrs, then washed once with PBS and scraped in TES buffer (see above). After $30 \mathrm{~min}$ incubation on ice, cells were dounce homogenized and the lysate was centrifuged at $19,000 \mathrm{x}$ g for $10 \mathrm{~min}$ at $4^{\circ} \mathrm{C}$. The supernatants were collected and used to detect the released cytochrome c, while the pellets were re-suspended in TES buffer and used to detect mitochondrial cytochrome c. Proteins were loaded on a $15 \%$ SDS-PAGE, blotted on a PVDF membrane and developed with the indicated antibodies.

\section{Intracellular staining}

For intracellular staining, cells were seeded on a $12 \mathrm{~mm}$ round coverslip in a standard 24 well plate in normal medium for 24 hrs. Cells were then washed twice in PBS and fixed with 2\% PFA/PBS for 15 min at RT. After permeabilization with $0.1 \%$ Triton X-100 for 10 min, cells were washed and blocked with 5\% FCS for 10 min and washed again. Samples were stained with affinity purified anti-Kv1.3 (1:100, affinitypurified Kv1.3 antibodies) and anti-Tim23 antibodies for $45 \mathrm{~min}$. Cells were washed and further incubated with secondary antibodies coupled to fluorescent dyes, i.e. Cy3-anti mouse IgG or Dylight649-anti rabbit IgG (Jackson Immunoresearch, PA, USA), for $45 \mathrm{~min}$ at RT. Samples were washed again, embedded in Mowiol and analyzed by confocal microscopy.

\section{Immunogold electron microscopy}

Cells were seeded on a dish for $24 \mathrm{hrs}$, washed and fixed in 2\% PFA and $0.1 \%$ glutaraldehyde in $0.1 \mathrm{M}$ cacodylate buffer for $1 \mathrm{~h}$ at RT. Cells were then washed in cacodylate buffer, gently scraped off the plate and collected. Samples were processed by the Imaging Center Essen (IMCES). Briefly, samples were dehydrated with increasing ethanol concentrations and infiltrated with a mixture of LR-Gold and ethanol with increasing LR-gold concentration at $-20^{\circ} \mathrm{C}$. Samples were then irradiated with UV light and polymerized for 56 hrs at $-20^{\circ} \mathrm{C}$. Samples were cut in ultrathin sections and washed. After blocking with $0.1 \%$ BSA in PBS for 30 min, samples were incubated with anti-Kv1.3 antibodies (Alamone) in 1\% BSA in TBS for $24 \mathrm{hrs}$ at $4^{\circ} \mathrm{C}$. Cells were washed again and incubated with $10 \mathrm{~nm}$-gold particle-coupled anti-rabbit antibodies (Aurion) in 1\% BSA in TBS for $3 \mathrm{~h}$ at RT. Finally, samples were washed again and stained with $1 \%$ uranyl-acetate for $10 \mathrm{~min}$. Samples were washed again and analyzed with a Zeiss transmission electron microscope (EM902A) at 80 $\mathrm{kV}$.

In vivo studies

To perform glioma injections, GL261 cells were trypsinized from a sub-confluent flask and collected. After washing twice in HEPES/Saline (20 mM HEPES pH 7.4, $132 \mathrm{mM} \mathrm{NaCl}, 1 \mathrm{mM} \mathrm{CaCl}, 0.7 \mathrm{mM} \mathrm{MgCl}, 0.8$ $\mathrm{mM} \mathrm{MgSO}_{4}, 5.4 \mathrm{mM} \mathrm{KCl}$ ), $2 \times 10^{4}$ cells were injected in the striatum of a mouse brain with an microliter syringe attached to a stereotactic device and an automatic injection system [19]. The mice were narcotized with fentanyl, midazolam and medetomidin, stereotactically fixed and a hole was drilled in the skull $2 \mathrm{~mm}$ lateral and $1 \mathrm{~mm}$ posterior to the bregma. The tumor cells were injected using an automatic microliter syringe attached to the stereotactic device. After completion of the surgical procedure mice were injected with antidote and allowed to recover. Glioma symptoms were monitored daily.

For survival analysis, treatments with clofazimine, PAPTP or PCARBTP were performed at days 5, 7, 9 and 11 post tumor injection by i.p. injection of the drug in $0.9 \% \mathrm{NaCl}$. All experiments were approved by the Animal Care and Use Committee of the Bezirksregierung Duesseldorf, Germany.

\section{Statistics}

Statistical analysis was performed by using analysis of variance (ANOVA) and a post hoc Bonferroni's multiple comparison test. Shown are mean \pm SD. 
Venturini et al.: Kv1.3 Inhibition Kills Glioblastoma Cells

\section{Results}

Kv1.3 is expressed in the plama membrane and mitochondria of different glioma cell lines

To test whether glioma cells express Kv1.3 in their plasma membrane, murine GL261 and human A172 and LN308 glioma cells were surface-stained with a FITC-labeled antiKv1.3 antibody. The signal obtained with glioma cells was compared to that of Jurkat cells, which are known to express Kv1.3 [8, 20]. K562, which do not express Kv1.3 [6, 21], were used as negative control. All three glioma cell lines expressed Kv1.3 (Fig. 1A). The signal was however lower than that of Jurkat cells, suggesting that the glioma cells express less surface Kv1.3. The presence of Kv1.3 in glioma cells was further demonstrated by Western blot on enriched membrane fractions (Fig. 1B) determining the total cellular expression of Kv1.3, which is comparable to that in Jurkat cells.

Since our previous data showed that cell death in other cell lines is mediated by mitoKv1.3 [6, 14, 22], we analyzed Kv1.3 expression in mitochondria of glioma cells. Western blot studies on isolated mitochondria from GL261 cells revealed Kv1.3 in the purified mitochondrial fraction (M) (Fig. 2A). The Western blot also shows that there is an increase in the intensity of the mitochondria marker Tim23 with increasing grade of purification, while the intensity of the tubulin band decreases and is completely missing in the mitochondrial fraction, indicating that the protocol yielded highly purified mitochondria. The mitochondrial localization of Kv1.3 was confirmed by confocal microscopy revealing a partial co-localization of Kv1.3 with mitochondria, labeled with anti-Tim23, in all three glioma cell lines (Fig. 2B). Location of Kv1.3 in mitochondria of GL261 was further shown by immunogold transmission electron microscopy (Fig. 2C). Kv1.3 was visualized with goldcoupled anti-Kv1.3 antibodies that appear in the electron microscopy studies as sharp black particles. The electron microscopy studies indicate expression of Kv1.3 in mitochondria (M), the endoplasmatic reticulum, the nuclear and the plasma membrane. Control studies using isotype-control immunoglobulins confirm the specificity of the stainings.

Taken together, these results show that Kv1.3 is expressed in the plasma membrane and in mitochondria of glioma cells.

Kv1.3 inhibitors induce cell death in glioma cells

Recent studies have shown that the membrane-permeant Kv1.3 inhibitors PAP-1, Psora-4 and clofazimine induce apoptosis in macrophages and different cancer cell lines, such as Jurkat (leukemic T lymphocytes), B16F10 (melanoma), SAOS-2 (sarcoma osteogenic),

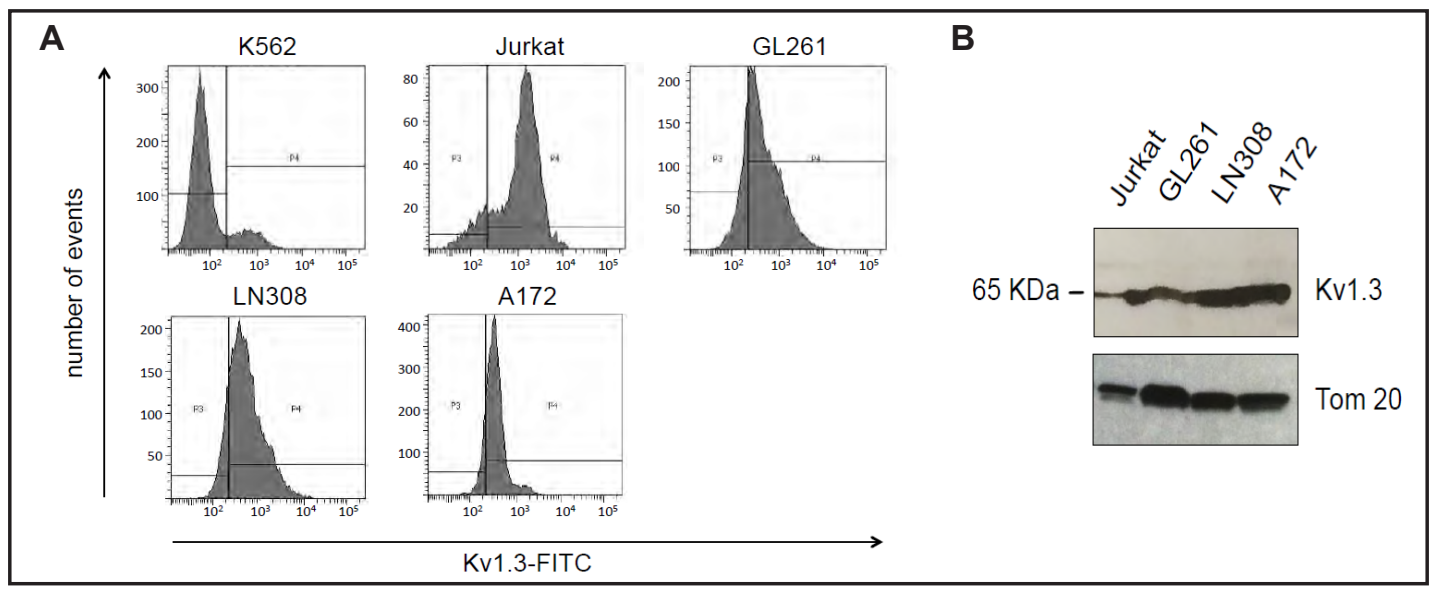

Fig. 1. Kv1.3 is expressed in glioma cells. (A, B) Glioma cells GL261, A172 and LN308 were analyzed for expression of plasma membrane Kv1.3 by flow cytometry after staining with FITC-coupled anti-Kv1.3 antibodies (A) or for total expression of Kv1.3 by Western blot studies of enriched membrane fractions (B). Shown are representative studies from 3 (A) and 2 (B) independent experiments with similar results. 


\section{SIGINAIS}

Fig. 2. Kv1.3 is expressed in the plasma membrane and in mitochondria of glioma cells. (A) Western blot studies revealed Kv1.3 expression in enriched membrane fractions (EM) and mitochondria (M). Tim23 served as mitochondrial marker, Tubulin as marker for cytoplasma. (B, C) Confocal microscopy of cells stained with Cy3-coupled anti-Kv1.3 and Dylight649-labelled anti-Tim23 antibodies (B) and transmission electron microscopy (C) of glioma cells stained with gold-coupled anti-Kv1.3 antibodies confirmed mitochondrial expression of the Kv1.3 channel. (B) The confocal microscopy studies revealed a partial co-localization of Kv1.3 with mitochondrial membranes that were stained with anti-Tim23 antibodies indicating mitochondrial expression of Kv1.3. (C) Localization of Kv1.3 in the electron microscopy studies was indicated by the sharp black gold particles. The gold particles localized to mitochondria (M), the endoplasmatic reticulum, the nuclear and the plasma membrane. Control studies using isotype control immunoglobulins confirmed the specificity of the stainings. Figures are representative for 2 independent experiments with similar results.

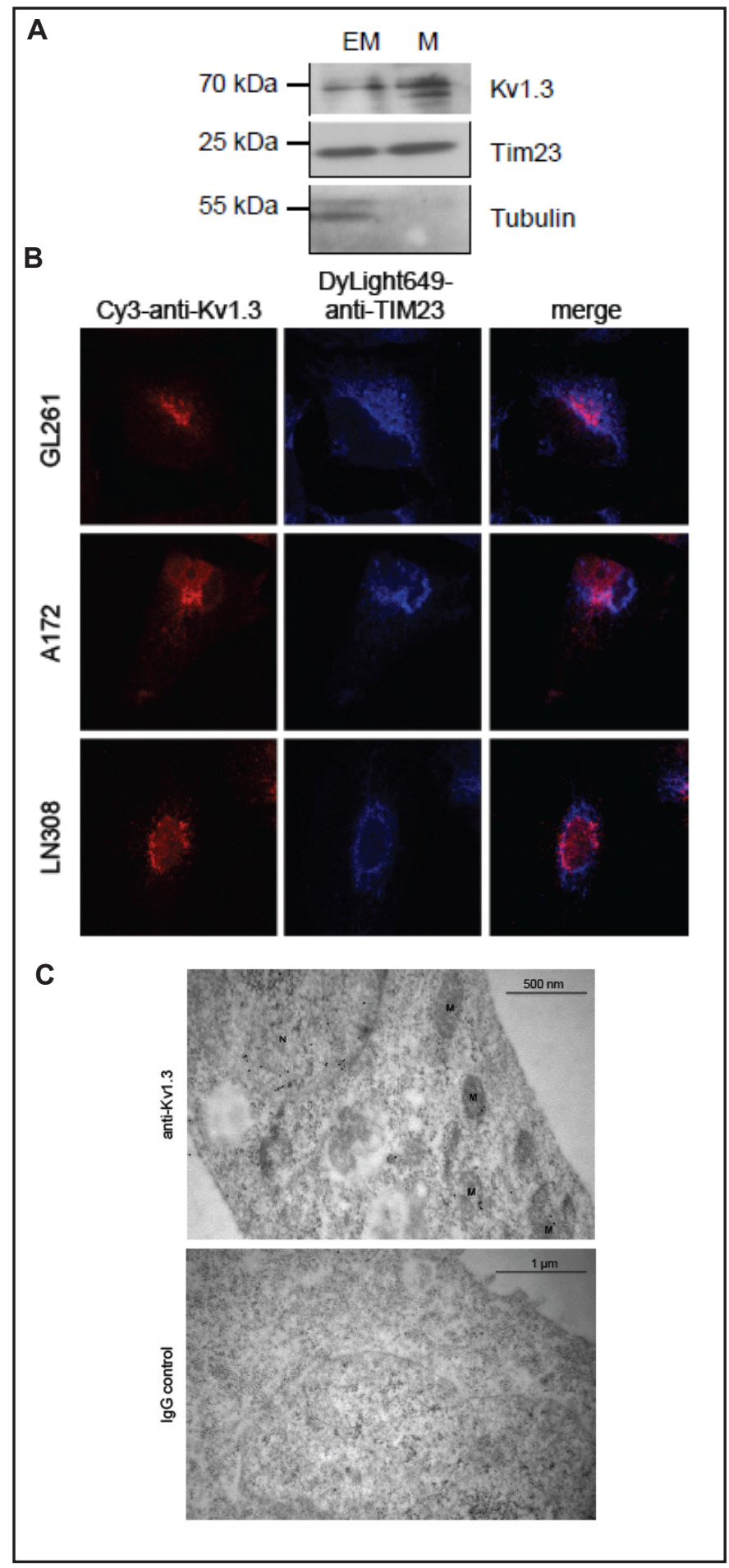

and ex vivo in B-cells from chronic lymphocytic leukemia patients (CLL) $[6,13,14]$. Thus, we determined the effects of different concentrations of the drugs on cell death in GL261, LN308 and A172 by Trypan blue staining after $24 \mathrm{hrs}$ incubation. Since many tumor cells extrude drugs by multidrug resistance pumps (MDR), MDR pump inhibitors (MDRi) Cyclosporine $\mathrm{H}(\mathrm{CSH})$ and probenecid were used in combination with Kv1.3 inhibitors to prevent export of the drugs from the intracellular milieu and, thus, amplify the effect of Kv1.3 blockers. However, all three cell lines GL261, LN308 and A172 (Fig. 3A) were rather resistant to the 


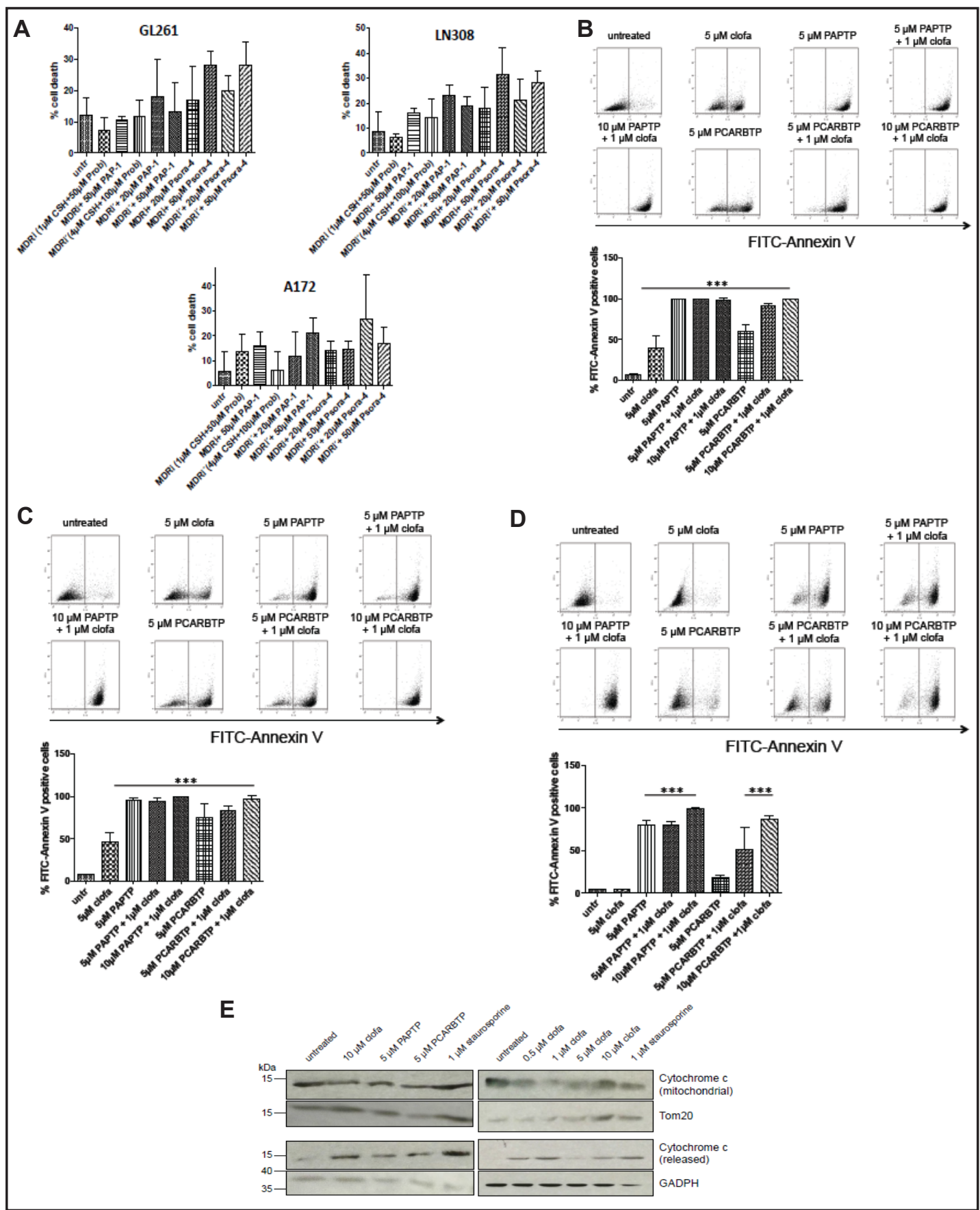

Fig. 3. Mitochondria-targeted Kv1.3 inhibitors induce cell death of glioma cell lines. (A) GL261, LN308 and A172 cells were treated for 24 hrs with different concentrations of Kv1.3 inhibitors PAP-1 and Psora- 4 in combination with cyclosporine $\mathrm{H}(\mathrm{CSH})$ and probenecid (Prob), the latter inhibitors of multiple drug resistance proteins (MDR). The different concentrations of the multiple drug resistance protein inhibitors are indicated by an apostrophe. Cell death was assessed by Trypan blue. The mean \pm SD of 3 independent experiments is shown. Significant differences between treated and untreated samples are indicated by asterisks ${ }^{*} \mathrm{p} \leq 0.05{ }^{* *} \mathrm{p} \leq 0.01$, one-way ANOVA/Bonferroni). Percentage of cell death was calculated as follows: $\%$ cell death $=(100 *$ number non-viable cells $) /$ total cells. Untr. = untreated. (B-D) GL261 (B), LN308 (C) and A172 (D) glioma cells were treated with clofazimine, PAPTP and PCARBTP. After $24 \mathrm{hrs}$, cells were stained with FITC-Annexin $\mathrm{V}$ and analyzed by flow cytometry. A representative experiment is displayed and the means \pm SD of cell death in three independent studies is given. Significant differences between treated and untreated 
samples are indicated by asterisks ( ${ }^{* * *} \mathrm{p} \leq 0.001$, one-way ANOVA/Bonferroni). (E) Gl261 cells were treated for $16 \mathrm{hrs}$ with clofazimine (clofa), PAPTP or PCARBTP, mitochondrial and cytosolic fractions were isolated, separated on 12\% SDS-PAGE, transferred to a PVDF membrane and developed for cytochrome c or Tom 20. GADPH served as loading control. The experiment was performed three times with similar results.

Fig. 4. Clofazimine and PAP-1 derivatives do not reduce glioma growth in vivo. Glioma-injected mice were left untreated, treated with $10 \mathrm{nmo-}$ l/g i.p. clofazimine, $4 \mathrm{nmol} / \mathrm{g}$ i.p. PAPTP or $8 \mathrm{nmol} / \mathrm{g}$ i.p. PCARBTP ( $\mathrm{n}=3$ each group) at days 5, 7, 9 and 11 post injection. The survival times and the means \pm SD are given.

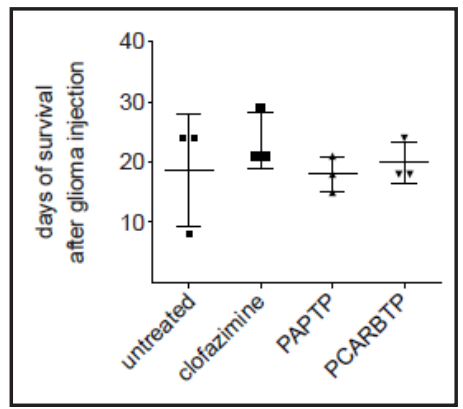

treatment with Psoralen derivatives Psora-4 and PAP-1, which induced only 20-30\% more cell death compared to the control.

We therefore investigated whether another Kv1.3 inhibitor, i.e. clofazimine, and the recently developed inhibitors of Kv1.3 [13] PAPTP and PCARBTP, that target the channel in mitochondria, may have a stronger effect on glioma cell survival. Thus, GL261, A172 and LN308 cells were treated with clofazimine, PAPTP or PCARBTP and cell death was assayed by flow cytometry upon staining of the cells with FITC-coupled Annexin V (Fig. 3B-D). PAPTP and PCARBTP were used alone or in combination with a low dose of clofazimine, which also acts as MDR inhibitor. After 24 hrs incubation, cells were collected, stained with FITCAnnexin $\mathrm{V}$ and analyzed by flow cytometry. Both mitochondria-targeted PAP-1 derivatives induced massive death in all tested glioma cell lines, achieving 90\% cell death in GL261 and LN308 cells after $24 \mathrm{hrs}$, while clofazimine displayed a weaker effect, inducing a maximum of $50 \%$ of apoptosis (Fig. 3B-D). Compared to GL261 and LN308 the glioma cell line A172 was most resistant to treatment with clofazimine, while PAPTP and PCARBTP efficiently induced cell death even in this resistant cancer cell line (Fig. 3B-D).

Previous studies demonstrated that the Kv1.3 inhibitors PAP-1, Psora- 4 and clofazimine induce the mitochondrial pathway of cell death [14]. To test whether PAPTP and PCARBTP also activate the intrinsic cell death pathway in glioma cells, we analyzed the release of cytochrome c from mitochondria by western blot analysis after treatment with clofazimine, PAPTP and PCARBTP. The results revealed a release of cytochrome $\mathrm{c}$ upon incubation of GL261 glioma cells with different clofazimine concentrations, PAPTP or PCARBTP (Fig. 3E). The classical intrinsic apoptosis inducer staurosporine was used as positive control.

\section{Kv1.3 inhibitors do not reduce glioma growth in vivo}

The in vitro data indicate a strong effect of Kv1.3 inhibitors on glioma cells. To test whether clofazimine, PAPTP and PCARBTP are also able to induce cancer cell death in vivo, we employed a syngeneic mouse glioma model, which does not require a deficient immune system and closely mimics growth characteristics of human GBM, including invasive and angiogenic properties [23]. Clofazimine, PAPTP or PCARBTP were intraperitoneally injected at days 5, 7, 9 and 11 post tumor cell injection and survival of the animals was assessed (Fig. 4). However, none of the drugs had a significant impact on the survival of tumor-bearing mice (Fig. 4).

\section{Discussion}

The results presented here indicate that Kv1.3 is expressed in different murine and human glioma cell lines, both in the plasma membrane and in mitochondria. Up to now, Kv1.3 had been identified in various glial tumors by the groups of Preussat and Felipe [24, 25]. Our 
Venturini et al.: Kv1.3 Inhibition Kills Glioblastoma Cells

study, showing expression of Kv1.3 in three different glioma cell lines, is in agreement with these studies and in addition it provides for the first time evidence on the mitochondrial expression of Kv1.3 in glioma. Dual localization of the channel, i.e. expression of Kv1.3 in mitochondrial and plasma membranes, had already been found in breast cancer MCF-7, prostate cancer PC3, osteosarcoma SAOS-2, melanoma B16F10, Jurkat T cell lymphoma [22, $26,27]$ and pancreas carcinoma [28]. In addition, recent data indicate the presence of Kv1.3 also in cis-Golgi [29] and in the nuclear membrane [30], which is also consistent with the present studies. The function of the cis-Golgi-located channels is unknown, while nuclear Kv1.3 has been suggested to impact on transcription factor activation via regulation of the nuclear membrane potential. Mitochondria-located Kv1.3 has been shown to play a crucial role in the regulation of cell death in various systems [13], but no connection of mitoKv1.3 with cell death had been demonstrated in glioma until now.

Here, we show that inhibition of Kv1.3 by relatively specific membrane permeable inhibitors triggers apoptosis in glioma cells. In particular, drugs that target mitochondria such as PAPTP or PCARBTP due to a positively charged modification in the molecule [14] are highly effective in killing GBM cells, while the precursor, PAP-1, and Psora-4, that are not targeted to mitochondria [14], are much less efficient with only up to $30 \%$ death of glioma cells. The A172 cell line is also resistant to clofazimine, at least partially. A tumor's multidrug resistance phenotype, especially expression of P-glycoprotein (p-gp) and of the multidrug resistance related proteins (MRPs), has been suggested to influence uptake of drugs and expression of p-gp has been shown to vary among glioma cell lines [31,32]. Apparently, A172 does not express detectable p-gp [32]; on the other hand, the finding that the MDR inhibitor probenecid increases the sensitivity of the cells to Kv1.3 inhibitors in a concentrationdependent manner points to an involvement of MDR pumps in the resistance of the tumor to Kv1.3 inhibitors. In any case, in two glioma lines $90 \%$ reduction of cell survival was observed with clofazimine, a drug with minimal side effects.

Our in vivo experiments on glioma failed to show a beneficial effect of the drug on orthotopic glioma, which is most likely due to the failure of the drug to accumulate in sufficient amounts in glioblastoma cells in vivo. The healthy blood-brain barrier (BBB) has been shown to be impermeable for clofazimine $[33,34]$. However, at present it is unknown whether the drug does not cross into tumor tissue although the blood brain barrier is altered in tumor tissues, whether the drug is rapidly consumed within the tumor tissue or whether the tumor cells are able to actively excrete the drug. The BBB permeability is altered only at the late stages of glioma development, but seems to remain mostly intact in terms of solute and drug permeability during early stages of tumor development [35]. Thus, in most GBM, and even more in lower grade gliomas, the BBB is preventing efficient passage of cancer chemotherapeutics [36] and this may also apply to our findings.

Therefore, a critical step during the development of these drugs for treatment of GBM and their translation into clinical treatments will be to increase their bioavailability within the glioblastoma tissue. One method could be the use of nanoparticles [37-39]. For instance, Gao and colleagues showed an increased IL-13 peptide uptake by glioma if the cytokine was coupled to nanoparticles [40]. Nanoparticles were also shown to increase paclitaxel efficacy in a malignant glioma model [41]. In addition, nanoparticles could be used in combination with physical techniques, such as ultrasound therapy, photodynamic therapy or irradiation [42]. Focus ultrasound exposure was recently used to enhance temozolomide delivery to glioma [43]. Promising results have recently been obtained using liposomes. Thus, e.g., PEGylated liposomes functionalised with two peptides with high affinities for transferrin receptors (TfRs) and Vascular Endothelial Growth Factor Receptor 2 (VEGFR 2), respectively, showed gratifying tumor-targeting properties in a mouse orthotopic glioma model [44]. In an analogous study [45] decoration with a TfRs-targeting peptide and (optionally) octaarginine $\left(\mathrm{R}_{8}\right.$; a well known membrane-penetration device) also provided significant drug delivery to the brain of glioma-bearing mice, although organ selectivity was not very marked. Interestingly, the presence of the multiple positive charges of the oligo-arginine chain 
Venturini et al.: Kv1.3 Inhibition Kills Glioblastoma Cells

determined a pronounced association with mitochondria in in vitro experiments. However, to get access to fast migrating glioma cells at the front of the tumor, further chemical modifications allowing the drugs to reach high concentrations in the tumor cells seem to be necessary. A strategy may envision the direct coupling of the drug to a cell-penetrating peptide, best if coupled to a homing peptide as well [46-49].

In summary, we demonstrate that inhibition of Kv1.3 in glioma by clofazimine, PAPTP or PCARBTP results in induction of death in a very high proportion of glioma cells. However, at present, a translation into the clinic requires modifications of these drugs and/or of the delivery method.

Acetylation is often used to improve the transport of a drug over the BBB, however, the present drugs lack a free $\mathrm{OH}$ group and this approach would not be an option.

We have previously shown that the membrane composition, in particular the formation of ceramide and ceramide-enriched membrane platforms, influences the function of Kv1.3, but also other ion channels and transporters [50-54]. Thus, it might be interesting whether targeted changes of sphingolipids using drugs that inhibit for instance the acid sphingomyelinase [55-59] also influence and promote the function of Kv1.3 inhibitors.

Our previous studies in mice did not shown any side effects of the doses of Kv1.3 inhibitors used in the present study, in particular we did not detect any apoptosis or necrosis of tissues $[13,14]$. However, Kv1.3 is expressed in the heart and application of the drug to humans must carefully monitor for any cardiac problems, in particular arrest or arrhythmia. In fact higher doses of the drugs showed cardiovascular side effects in mice and we therefore treated the mice with a safe dose. Further, mice deficient for Kv1.3 have some hearing problems and, thus, side effects on the inner ear must be also monitored.

In summary, we demonstrate that inhibition of Kv1.3 in glioma by clofazimine, PAPTP or PCARBTP results in induction of death in a very high proportion of glioma cells. However, at present, a translation into the clinic requires modifications of these drugs and/or of the delivery method.

\section{Acknowledgements}

The study was supported by DFG grant GRK-2098/1-TP3 to KAB, GRK-1739/-2-TP11 to EG and AIRC grant 11814 to I.S, BIRD162511 to LL, the INTEROMICS program of the Italian MIUR to MZ.

\section{Disclosure Statement}

The authors have no conflicts to declare.

\section{References}

1 Siegel R, Naishadham D, Jemal A: Cancer statistics, 2013. CA Cancer J Clin 2013;63:11-30.

-2 Stupp R, Mason WP, van den Bent MJ, Weller M, Fisher B, Taphoorn MJ, Belanger K, Brandes AA, Marosi

C, Bogdahn U, Curschmann J, Janzer RC, Ludwin SK, Gorlia T, Allgeier A, Lacombe D, Cairncross JG, Eisenhauer E, Mirimanoff RO, European Organisation for Research and Treatment of Cancer Brain Tumor and Radiotherapy Groups, National Cancer Institute of Canada Clinical Trials Group: Radiotherapy plus concomitant and adjuvant temozolomide for glioblastoma. N Engl J Med 2005;352:987-996.

-3 Weller M, Wick W, Aldape K, Brada M, Berger M, Pfister S, Nishikawa R, Rosenthal M, Wen PY, Stupp R, Reifenberger G. Glioma. Nat Rev Dis Primers 2015;1:15017

4 Johnson DR, Leeper HE, Uhm JH: Glioblastoma survival in the United States improved after Food and Drug Administration approval of bevacizumab: a population-based analysis. Cancer 2013;119:3489-3495. 
5 Arcangeli A, Crociani O, Lastraioli E, Masi A, Pillozzi S, Becchetti A: Targeting ion channels in cancer: a novel frontier in antineoplastic therapy. Curr Med Chem 2009;16:66-93.

6 Leanza L, O'Reilly P, Doyle A, Venturini E, Zoratti M, Szegezdi E, Szabò I: Correlation between potassium channel expression and sensitivity to drug-induced cell death in tumor cell lines. Curr Pharm Des 2014;20:189-200.

7 Comes N, Serrano-Albarrás A, Capera J, Serrano-Novillo C, Condom E, Ramón YCS, Ferreres JC, Felipe A: Involvement of potassium channels in the progression of cancer to a more malignant phenotype. Biochim Biophys Acta 2015;1848:2477-2492.

-8 Szabò I, Bock J, Jekle A, Soddemann M, Adams C, Lang F, Zoratti M, Gulbins E: A novel potassium channel in lymphocyte mitochondria. J Biol Chem 2005;280:12790-12798.

-9 Szabò I, Bock J, Grassmé H, Soddemann M, Wilker B, Lang F, Zoratti M, Gulbins E: Mitochondrial potassium channel Kv1.3 mediates Bax-induced apoptosis in lymphocytes. Proc Natl Acad Sci U S A 2008;105:1486114866.

10 Annis MG, Soucie EL, Dlugosz PJ, Cruz-Aguado JA, Penn LZ, Leber B, Andrews DW: Bax forms multispanning monomers that oligomerize to permeabilize membranes during apoptosis. EMBO J 2005;24:2096-2103.

11 Szabò I, Soddemann M, Leanza L, Zoratti M, Gulbins E: Single-point mutations of a lysine residue change function of Bax and Bcl-xL expressed in Bax- and Bak-less mouse embryonic fibroblasts: novel insights into the molecular mechanisms of Bax-induced apoptosis. Cell Death Differ 2011;18:427-438.

12 Leanza L, Trentin L, Becker KA, Frezzato F, Zoratti M, Semenzato G, Gulbins E, Szabò I: Clofazimine, Psora-4 and PAP-1, inhibitors of the potassium channel Kv1.3, as a new and selective therapeutic strategy in chronic lymphocytic leukemia. Leukemia 2013;27:1782-1785.

-13 Leanza L, Romio M, Becker KA, Azzolini M, Trentin L, Managò A, Venturini E, Zaccagnino A, Mattarei A, Carraretto L, Urbani A, Kadow S, Biasutto L, Martini V, Severin F, Peruzzo R, Trimarco V, Egberts JH, Hauser C, Visentin A, Semenzato G, Kalthoff H, Zoratti M, Gulbins E, Paradisi C, Szabo I: Direct pharmacological targeting of a mitochondrial ion channel selectively kills tumor cells in vivo. Cancer Cell 2017;31:516-531.

14 Leanza L, Henry B, Sassi N, Zoratti M, Chandy KG, Gulbins E, Szabò I: Inhibitors of mitochondrial Kv1.3 channels induce Bax/Bak-independent death of cancer cells. EMBO Mol Med 2012;4:577-593.

15 Herrlinger U, Aulwurm S, Strik H, Weit S, Naumann U, Weller M: MIP-1alpha antagonizes the effect of a GMCSF-enhanced subcutaneous vaccine in a mouse glioma model. J Neurooncol 2004;66:147-154.

-16 Rieger J, Stander M, Loschmann PA, Heneka M, Dichgans J, Klockgether T, Weller M: Synthesis and biological effects of NO in malignant glioma cells: modulation by cytokines including CD95L and TGF-beta, dexamethasone, and p53 gene transfer. Oncogene 1998;17:2323-2332.

17 Krishnan S, Szabo E, Burghardt I, Frei K, Tabatabai G, Weller M: Modulation of cerebral endothelial cell function by TGF-beta in glioblastoma: VEGF-dependent angiogenesis versus endothelial mesenchymal transition. Oncotarget 2015;6:22480-22495.

18 Sassi N, De Marchi U, Fioretti B, Biasutto L, Gulbins E, Franciolini F, Szabò I, Zoratti M: An investigation of the occurrence and properties of the mitochondrial intermediate-conductance Ca2+-activated K+ channel mtKCa3.1. Biochim Biophys Acta 2010;1797:1260-1267.

-19 Wirsching HG, Krishnan S, Florea AM, Frei K, Krayenbühl N, Hasenbach K, Reifenberger G, Weller M, Tabatabai G: Integrin control of the transforming growth factor- $\beta$ pathway in glioblastoma. Brain 2014;137:433-448.

20 Cahalan MD, Chandy KG: The functional network of ion channels in T lymphocytes. Immunol Rev 2009;231:59-87.

21 Smith GA, Tsui HW, Newell EW, Jiang X, Zhu XP, Tsui FW, Schlichter LC: Functional up-regulation of HERG K+ channels in neoplastic hematopoietic cells. J Biol Chem 2002;277:18528-18534.

22 Gulbins E, Sassi N, Grassmé H, Zoratti M, Szabò I: Role of Kv1.3 mitochondrial potassium channel in apoptotic signalling in lymphocytes. Biochim Biophys Acta 2010;1797:1251-1259.

23 Jacobs VL, Valdes PA, Hickey WF, De Leo JA: Current review of in vivo GBM rodent models: emphasis on the CNS-1 tumour model. ASN Neuro 2011;3:e00063.

24 Preussat K, Beetz C, Schrey M, Kraft R, Wolfl S, Kalff R, Patt S: Expression of voltage-gated potassium channels Kv1.3 and Kv1.5 in human gliomas. Neurosci Lett 2003;346:33-36. 
Venturini et al.: Kv1.3 Inhibition Kills Glioblastoma Cells

-25 Bielanska J, Hernández-Losa J, Perez-Verdaguer M, Moline T, Somoza R, Ramón YCS, Condom E, Ferreres JC, Felipe A: Voltage-dependent potassium channels Kv1.3 and Kv1.5 in human cancer. Curr Cancer Drug Targets 2009;9:904-914.

26 Bednarczyk P, Kowalczyk JE, Beresewicz M, Dolowy K, Szewczyk A, Zablocka B: Identification of a voltage-gated potassium channel in gerbil hippocampal mitochondria. Biochem Biophys Res Commun 2010;397:614-620.

27 Vicente R, Escalada A, Villalonga N, Texidó L, Roura-Ferrer M, Martín-Satué M, López-Iglesias C, Soler C, Solsona C, Tamkun MM, Felipe A: Association of Kv1.5 and Kv1.3 contributes to the major voltagedependent K+ channel in macrophages. J Biol Chem 2006;281:37675-37685.

-28 Zaccagnino A, Pilarsky C, Tawfik D, Sebens S, Trauzold A, Novak I, Schwab A, Kalthoff H: In silico analysis of the transportome in human pancreatic ductal adenocarcinoma. Eur Biophys J 2016;45:749-763.

29 Zhu J, Yan J, Thornhill WB: The Kv1.3 potassium channel is localized to the cis-Golgi and Kv1.6 is localized to the endoplasmic reticulum in rat astrocytes. The FEBS J 2014;281:3433-3445.

-30 Jang SH, Byun JK, Jeon WI, Choi SY, Park J, Lee BH, Yang JE, Park JB, O'Grady SM, Kim DY, Ryu PD, Joo SW, Lee SY: Nuclear localization and functional characteristics of voltage-gated potassium channel Kv1.3. J Biol Chem 2015;290:12547-12557.

- 31 Roller A, Bähr OR, Streffer J, Winter S, Heneka M, Deininger M, Meyermann R, Naumann U, Gulbins E, Weller M: Selective potentiation of drug cytotoxicity by NSAID in human glioma cells: the role of COX-1 and MRP. Biochem Biophys Res Commun 1999;259:600-605.

-32 Alexiou GA, Xourgia X, Vartholomatos E, Tsiouris S, Kalef-Ezra JA, Fotopoulos AD, Kyritsis AP: Comparison of $(99 \mathrm{~m})$ tc-tetrofosmin and $(99 \mathrm{~m})$ tc-sestamibi uptake in glioma cell lines: the role of p-glycoprotein expression. Int J Mol Imaging 2014;2014:471032.

-33 Mansfield RE: Tissue concentrations of clofazimine (B663) in man. Am J Trop Med Hyg 1974;23:11161119.

-34 Baik J, Stringer KA, Mane G, Rosania GR: Multiscale distribution and bioaccumulation analysis of clofazimine reveals a massive immune system-mediated xenobiotic sequestration response. Antimicrob Agents Chemother 2013;57:1218-1230.

-35 On NH, Savant S, Toews M, Miller DW: Rapid and reversible enhancement of blood-brain barrier permeability using lysophosphatidic acid. J Cereb Blood Flow Metab 2013;33:1944-1954.

-36 van Tellingen O, Yetkin-Arik B, de Gooijer MC, Wesseling P, Wurdinger T, de Vries HE: Overcoming the blood-brain tumor barrier for effective glioblastoma treatment. Drug Resist Update 2015;19:1-12.

37 Karim R, Palazzo C, Evrard B, Piel G: Nanocarriers for the treatment of glioblastoma multiforme: Current state-of-the-art. J Control Release 2016;227:23-37.

-38 Pourgholi F, Hajivalili M, Farhad JN, Kafil HS, Yousefi M: Nanoparticles: Novel vehicles in treatment of glioblastoma. Biomed Pharmacother 2016;77:98-107.

-39 Frosina G: Nanoparticle-mediated drug delivery to high-grade gliomas. Nanomedicine 2016;12:1083-1093.

40 Gao H, Yang Z, Zhang S, Cao S, Shen S, Pang Z, Jiang X: Ligand modified nanoparticles increases cell uptake, alters endocytosis and elevates glioma distribution and internalization. Sci Rep 2013;3:2534.

-41 Nance E, Zhang C, Shih TY, Xu Q Schuster BS, Hanes J: Brain-penetrating nanoparticles improve paclitaxel efficacy in malignant glioma following local administration. ACS Nano 2014;8:10655-10664.

-42 Tamborini M, Locatelli E, Rasile M, Monaco I, Rodighiero S, Corradini I, Franchini MC, Passoni L, Matteoli $\mathrm{M}$ : A combined approach employing chlorotoxin-nanovectors and low dose radiation to reach infiltrating tumor niches in glioblastoma. ACS Nano;10:2509-2520.

43 Liu HL, Huang CY, Chen JY, Wang HY, Chen PY, Wei KC: Pharmacodynamic and therapeutic investigation of focused ultrasound-induced blood-brain barrier opening for enhanced temozolomide delivery in glioma treatment. PloS One 2014;9:e114311.

44 Zhang Y, Zhai M, Chen Z, Han X, Yu F, Li Z, Xie X, Han C, Yu L, Yang Y, Mei X: Dual-modified liposome codelivery of doxorubicin and vincristine improve targeting and therapeutic efficacy of glioma. Drug Deliv 2017;24:1045-1055.

-45 Mu LM, Bu YZ, Liu L, Xie HJ, Ju RJ, Wu JS, Zeng F, Zhao Y, Zhang JY, Lu WL: Lipid vesicles containing transferrin receptor binding peptide TfR-T12 and octa-arginine conjugate stearyl-R8 efficiently treat brain glioma along with glioma stem cells. Sci Rep 2017;7:3487. 


\section{SIGINAIS}

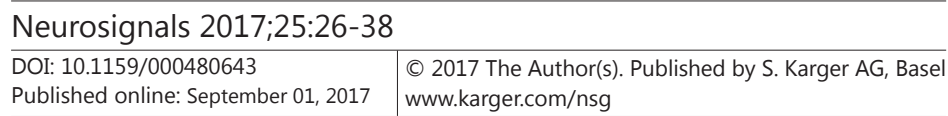

Venturini et al.: Kv1.3 Inhibition Kills Glioblastoma Cells

46 Li Y, Zheng X, Gong M, Zhang J: Delivery of a peptide-drug conjugate targeting the blood brain barrier improved the efficacy of paclitaxel against glioma. Oncotarget 2016;7:79401-79407.

-47 Zhang L, Zhang Y, Tai L, Jiang K, Xie C, Li Z, Lin YZ, Wei G, Lu W, Pan W: Functionalized cell nucleuspenetrating peptide combined with doxorubicin for synergistic treatment of glioma. Acta Biomater 2016;42:90-101.

48 Dissanayake S, Denny WA, Gamage S, Sarojini V: Recent developments in anticancer drug delivery using cell penetrating and tumor targeting peptides. J Control Release 2017;250:62-76.

-49 Guidotti G, Brambilla L, Rossi D: Cell-Penetrating Peptides: From basic research to clinics. Trends Pharmacol Sci 2017;38:406-424.

50 Bock J, Gulbins E: The transmembranous domain of CD40 determines CD40 partitioning into lipid rafts. FEBS Lett 2003;534:169-174.

-51 Lee H, Rotolo JA, Mesicek J, Penate-Medina T, Rimner A, Liao W-C, Yin X, Ragupathi G, Ehleiter D, Gulbins E, Zhai D, Reed JC, Haimovitz-Friedman A, Fuks Z, Kolesnick R: Mitochondrial ceramide-rich macrodomains functionalize Bax upon irradiation. PLoS One 2011;6:e19783.

-52 Nicolay JP, Gatz S, Liebig G, Gulbins E, Lang F: Amyloid induced suicidal erythrocyte death. Cell Physiol Biochem 2007;19:175-184.

-53 Zhang AY, Yi F, Jin S, Xia M, Chen QZ, Gulbins E, Li PL: Acid sphingomyelinase and its redox amplification in formation of lipid raft redox signaling platforms in endothelial cells. Antioxid Redox Signal 2007;9:817828.

-54 Lang F, Madlung J, Uhlemann AC, Risler T, Gulbins E: Cellular taurine release triggered by stimulation of the Fas(CD95) receptor in Jurkat lymphocytes. Pflügers Arch 1998;436:377-383.

55 Kornhuber J, Tripal P, Reichel M, Terfloth L, Bleich S, Wiltfang J, Gulbins E: Identification of new functional inhibitors of acid sphingomyelinase using a structure-property-activity relation model. J Med Chem 2008;51:219-237.

-56 Gulbins E, Palmada M, Reichel M, Lüth A, Böhmer C, Amato D, Müller CP, Tischbirek CH, Groemer TW, Tabatabai G, Becker KA, Tripal P, Staedtler S, Ackermann TF, v. Brederode J, Alzheimer C, Weller M, Lang UE, Kleuser B, Grassmé H, Kornhuber J: Acid sphingomyelinase/ceramide system mediates effects of antidepressant drugs. Nat Med 2013;19:934-938.

-57 Nährlich L, Mainz JG, Adams C, Engel C, Herrmann G, Icheva V, Lauer J, Deppisch C, Wirth A, Unger K, Graepler-Mainka U, Hector A, Heyder S, Stern M, Döring G, Gulbins E, Riethmüller J: Therapy of CF-patients with amitriptyline and placebo - a randomised, double-blind, placebo-controlled phase IIb multicenter, cohort study. Cell Physiol Biochem 2013;31:505-512.

58 Riethmüller J, Anthonysamy J, Serra E, Schwab M, Döring G, Gulbins E: Therapeutic efficacy and safety of amitriptyline in patients with cystic fibrosis. Cell Physiol Biochem 2009;24:65-72.

-59 Becker KA, Riethmüller J, Lüth A, Döring G, Kleuser B, Gulbins E: Acid sphingomyelinase inhibitors normalize pulmonary ceramide and inflammation in cystic fibrosis. Am J Respir Cell Mol Biol 2009;42:716724. 